\title{
From famous to infamous: Psychiatric aspects of the fall from grace
}

It's an all-too-common news item: The crash and burn of yet another politician, celebrity, or prominent individual. It's painful to watch someone who spent years to achieve the status of a household name suddenly, and often ignominiously, lose it all. This is the equivalent of a human train wreck.

Some adversaries (who doesn't have a few?) will rejoice or express schadenfreude, but many people will experience some empathy or sorrow as they witness the implosion of a celebrity. Fans, followers, or voters may grieve as the object of their respect and adulation falls off the high pedestal of fame. What starts as a drip-drip of rumors and innuendos soon eventuates in a denouement. And with time, as additional public figures fall from grace, the previous casualties will become mere footnotes in the annals of human selfdestruction. Their loss of face, shame, and wrenching emotional and financial toll will be forgotten from the public's collective memory, but the embers of bitterness and regret will continue to smolder in the hearts and souls of those who inadvertently contributed to their own social or professional demise due to a mistake, error of judgement, or plain old-fashioned stupidity. For the fallen, forgiveness and redemption are hard to come by.

Oh, how the mighty have fallen over centuries, and they include historical figures such as kings, military leaders, religious leaders, and politicians. The fall from grace in the past often led to executions, excommunication, or persecution. In the contemporary era, the oppressive "cancel culture" will mercilessly discard anyone, regardless of stature, after only 1 "wrong" tweet. In the digital age of mass communication, being "cancelled" is a frequent fall from grace and is the equivalent of being ostracized from millions of denizens on social media, which can spell doom for one's career and social interactions.

The list of those whose careers ended calamitously include many familiar names, but I will only cite their prominent roles (you can easily guess their names!):

- emperors, kings, presidents, prime ministers, and political demagogues

- congressmen, senators, governors, and mayors

- Nobel Laureates (a Medicine and Physiology winner went to prison for pedophilia, and a Peace Prize winner fell from grace for supporting a military dictatorship)

- Cardinals and bishops in various countries (for sexual or financial crimes)

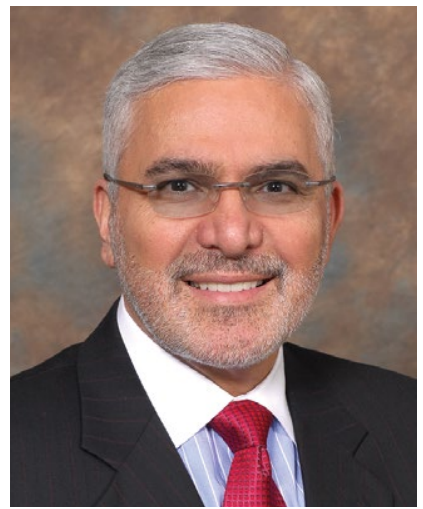

Henry A. Nasrallah, MD Editor-in-Chief

doi: 10.12788/cp.0177

\section{Perhaps the most}

common thread across

all the tragic cases

of self-destruction is hubris

To comment on this

editorial or other topics

of interest:

henry.nasrallah

@currentpsychiatry.com 
Editorial Staff

EDITOR Jeff Bauer

SENIOR EDITOR Sathya Achia Abraham

ASSISTANT EDITOR Matthew Wyles

WEB EDITOR Kathryn Wighton

Art \& Production Staff

CREATIVE DIRECTOR Louise Koenig

ART DIRECTOR Pat Fopma

DIRECTOR, JOURNAL MANUFACTURING Michael Wendt

PRODUCTION MANAGER Donna Pituras

Publishing Staff

PUBLISHER Sharon Finch

DIRECTOR EBUSINESS DEVELOPMENT

Alison Paton

SENIOR DIRECTOR OF SALES

Tim LaPella

Editor-in-Chief Emeritus

James Randolph Hillard, MD

Frontline Medical Communications

VP, SALES Mike Guire

VP, DIGITAL CONTENT \& STRATEGY

Amy Pfeiffer

PRESIDENT, CUSTOM SOLUTIONS

JoAnn Wahl

CIRCULATION DIRECTOR Jared Sonners

In affiliation with Global Academy for Medical Education, LLC

PRESIDENT David J. Small, MBA

\section{FRONTLNEE MLedge}

7 Century Drive, Suite 302

Parsippany, NJ 07054

Tel: (973) 206-3434

Fax: (973) 206-9378

www.frontlinemedcom.com

Subscription Inquiries:

subscriptions@mdedge.com

Published through an educational partnership with
- billionaires, often for erratic personal lives

- sport legends, including decorated athletes and coaches of college and professional teams

- world chess masters

- Wall Street moguls

- Hollywood celebrities, including actors and directors, some with Oscars and related recognitions

- television news anchors and commentators

- comedians of various stripes

- CEOs of major media companies

- talk show hosts watched by millions

- celebrated musicians (classical, pop, rap, or blues)

- university presidents

- others in esteemed positions (including some psychiatrists).

\section{Why is this so common?}

From a psychiatric perspective, the most compelling question is why is the fall from grace so common? What are the transgressions, flaws, and shortcomings of successful individuals whose reputations end up smeared or who lose everything they worked for? Why do high achievers, talented and successful, at the apogee of fame and fortune, lose it all with nary a chance for recovery?

The answer is all too obvious: human frailties. Successful persons are by no means immune from poor judgment. They can be as error-prone as the rest of us mortals. Having robust cognitive intelligence can be undermined by stunted emotional intelligence or poor interpersonal or social judgment. In Freudian terms, famous people who crash and burn may have a "Swiss cheese superego" that allows their id to viciously weaken their ego. From a neuroscience perspective, their limbic system conquers their cortical circuitry with relentless innate forces, including:

- fervent sexual appetite, compounded by the cockiness that comes with fame

- felonious paraphilias, such as pedophilia or public indecency

- intense greed that clouds one's judgment (a trait exhibited by some ultra-rich persons)

- narcissism, either inborn or acquired with unexpected success and power

- impulsivity and recklessness, with injurious words or actions.

- substance use.

Consideration should be given to psychopathology. Some may have a personality disorder. Others may be both blessed and cursed with hypomania that leads to high achievement but also to foolish and impulsive behavior. ${ }^{1}$ Some may have maladaptive social skills seen in autism spectrum disorder (recently, a very prominent and innovative billionaire casually announced that he has autistic traits). And others my have limited coping skills to deal with fame and fortune and unwittingly end up shooting themselves in both feet.

But perhaps the most common thread across all the tragic cases of self-destruction is hubris. As humans become rich, famous, or powerful, they gradually develop the fallacious belief that they can get away with anything because they have masses of fans and followers who "love them no matter what." This dangerous "acquired narcissism" is an unfortunate byproduct of success. Humility is rare among celebrities and powerful leaders. Modest celebrities almost never fall from grace and are endowed with an innate antidote to self-aggrandizement. A few years ago, I wrote an editorial in CURRENT Psychiatry titled "Should psychiatry list hubris in DSM-V?"2 While hubris is not regarded as a psychiatric disorder, it 
is certainly an affliction that often ends badly. The mental repercussions can include depression, anxiety, posttraumatic stress disorder, despair, and even falling on one's sword. Hubris can be a fatal flaw with devastating consequences to one's career. Perhaps those who aspire to become a celebrity should receive mentorship about hubris as a hazard of fame and fortune, when they are still in the "rising star" stage of their lives.

In contemporary society, with the era of social media and toxic political zeitgeist, there are many inadvertent "opportunities" to stumble and ruin one's career by uttering an "unacceptable" word or dispatching an "offensive tweet" or posting a politically incorrect photo. And even if one is currently careful, there are now social media detectives and fact-finding "archeologists" who can excavate and disseminate the faux pas, peccadillos, or misdeeds from a prominent person's immature youth, which will destroy a famous person overnight. That can be a nightmare for anyone who becomes a bona fide celebrity after years of working hard to get there.

High achievers: Beware!

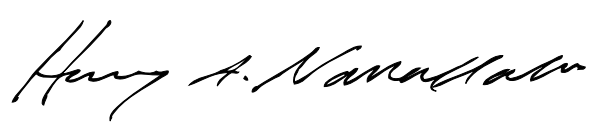

Henry A. Nasrallah, MD

Editor-in-Chief

\section{References}

1. Gartner JD. The hypomanic edge: the link between (a little) craziness and (a lot of) success in America. Simon \& Schuster; 2005.

2. Nasrallah HA. Should psychiatry list hubris in DSM-V? Current Psychiatry. 2008;7(12):14-15.
Hubris can be a fatal flaw with devastating consequences to one's

\section{career}

